\title{
Materials and engineering: An evolving landscape
}

\section{Dipankar Banerjee and James C. Williams}

The evolution of materials; their synthesis, shaping, and performance; and the engineering of artifacts and systems to meet societal demands are inextricably interwoven. In this article, we describe an evolving scenario of the relationship between materials and engineering that provides a framework for the articles that explore various facets of this theme in this special issue of MRS Bulletin.

\section{Introduction}

Starting with stone in prehistoric times followed by copper and then iron and steel by the 19th century, the number of materials available to engineers was perhaps a few hundred. Today, this number stands at about 160,000 , most of which were discovered or developed in the past 100 years. ${ }^{1,2}$ Figure 1 shows an example of this extraordinary growth of materials choice in strength-density space in three Ashby maps. ${ }^{3}$

The precursors to the discipline of materials engineering were established in the distant past. Metal forming emerged around 3000-4000 BC with the heating of native copper to make tools and other items. In approximately the same period, copper was smelted from its ore in Timna in Israel. The third great innovation, alloying, appears to have occurred between $2000 \mathrm{BC}$ and $3000 \mathrm{BC}$ in Egypt, where the earliest bronzes have been found. Together, this triad of events laid the foundations for the paradigm on which materials science is based: the relationship among composition, processing, structure, and properties.

In this article, we explore the impact of the expanding choice of materials and the related processes of making, shaping, and joining; the evolving integration of materials development with the design of products and systems; and attempts to accelerate materials insertion. We also discuss the emerging topography of scarcity and sustainability, which will drive the use of materials in the future.

\section{The role of materials in engineering}

The relationship between artifacts and materials can be indirect. As Mark Miodownik, the author of one of the articles in this issue, points out in his book Stuff Matters, ${ }^{4}$ the pyramids could not have been built without copper tools (Figure 2), which resulted from civilizations' entry into the metal age with the extraction of copper from malachite. Certainly, the emergence of the blast furnace in China in about $200 \mathrm{BC}$, culminating in large-scale steel production through $1900 \mathrm{AD}$, laid the platform for the industrial use of materials that have revolutionized the way we travel, produce energy, and inform and interact with each other.

The increased capability of commercial aircraft, for example, as measured by range and operating cost, has "shrunk" the world. Figure 3a shows the dramatic decrease in fuel consumption per passenger achieved in air travel over the past few decades. Improvements in the durability and reliability of engines used on commercial aircraft have transformed flight in ways that most of us do not realize. When the Boeing 707, the first large, commercial, jet-powered aircraft, entered service in the late 1950 s, the goal was for the engines to stay "on wing" between major maintenance procedures for $500 \mathrm{flight}$ hours. Today, engines used on long-haul commercial aircraft routinely stay on wing for 20,000-25,000 h.

Aircraft can now fly nonstop as long as $15-20 \mathrm{~h}$, including long segments over water or other terrain within single-engine 


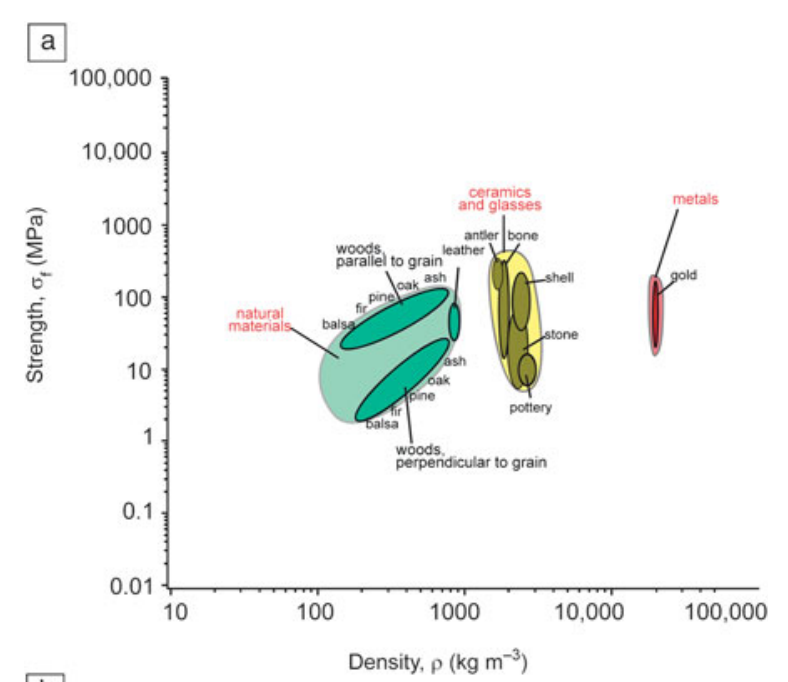

$\mathrm{b}$

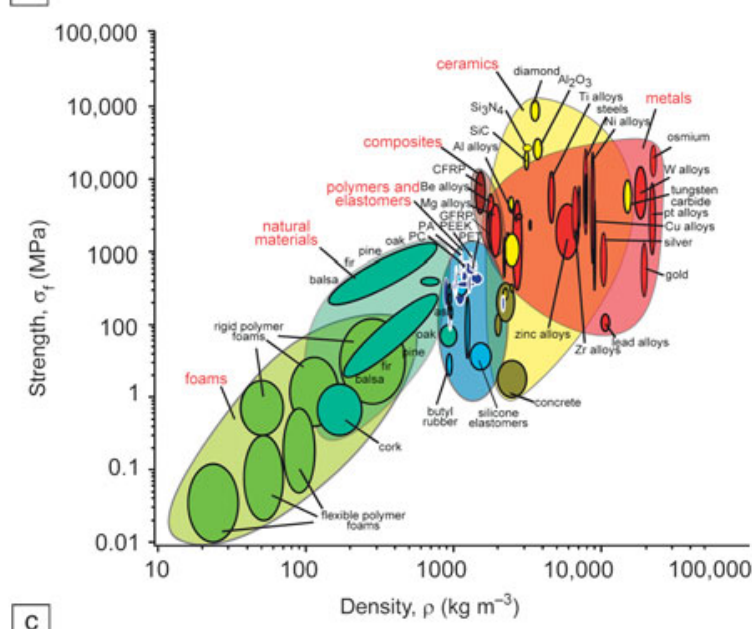

c

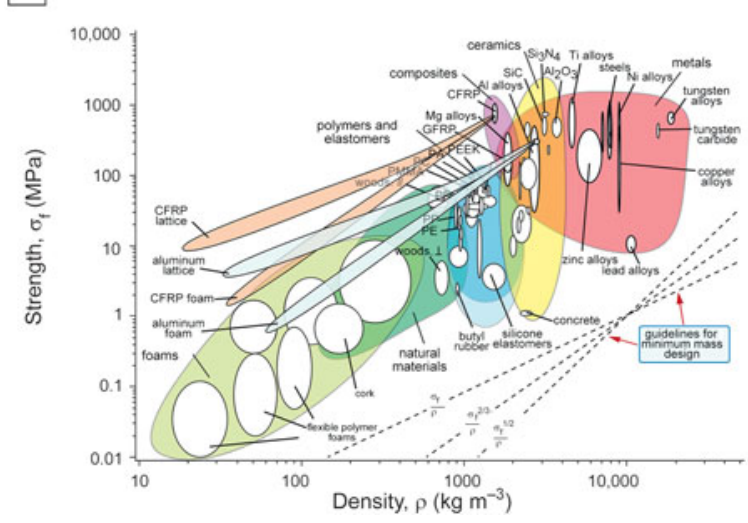

Figure 1. The rapidly growing choice of materials available to structural engineers illustrated in strength-density space: ${ }^{3}$ (a) prehistory, (b) present day, and (c) present day with architected materials whose properties emerge from the interaction of materials with their shape. Note: CFRP, carbon-fiber-reinforced plastic; GFRP, glass fiber-reinforced polymer; PA, polyamide; PC, polycarbonate; PEEK, poly(ether ether ketone); PMMA, poly(methyl methacrylate). Reproduced with permission from Reference 3. (C) 2010 Royal Society.

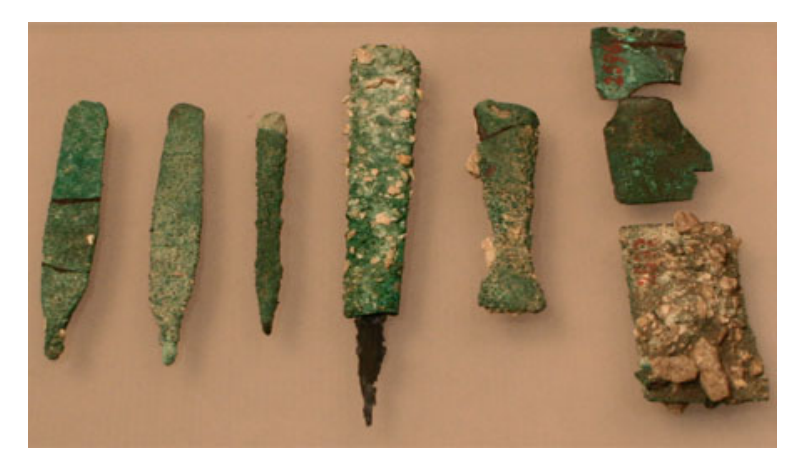

Figure 2. Egyptian copper tools from Giza (undated). Figure obtained from Wikimedia Commons. ${ }^{5}$

flying range of a suitable airport. This is due to the vastly reduced frequency of in-flight engine shutdowns and increased fuel efficiency and thrust/weight ratio of engines that power twin-engine commercial aircraft. Although it is essentially impossible to disaggregate improvements to most products into specific contributions from any engineering discipline, the article in this issue by Boyer et al. demonstrates how materials have played a significant enabling role in driving aircraft performance. Figure 3c-e illustrates cast nickel-based superalloy airfoils in the equiaxed, directionally solidified, and monocrystal forms, which have enabled significant increases in the turbine entry temperature of jet engines through a remarkable combination of processing and chemistry. The chemistry of these nickel-based alloys has evolved from solid solutionstrengthened alloys of nickel and chromium (used in the first Whittle jet engine) to precipitation-hardened alloys strengthened by intermetallic $\mathrm{Ni}_{3} \mathrm{Al}$ with complex compositions involving the addition of cobalt, aluminum, titanium, tantalum, molybdenum, tungsten, niobium, rhenium, ruthenium, and other elements that balance the diversity of properties required in various applications, together with processability in the form of the investment casting process. ${ }^{8}$ The casting processes that have evolved to manufacture these intricate, hollow, internally cooled turbine blades were used in South India as the "beeswax process" to cast idols of gods with bronzes during the 9 th to the 12 th centuries (Figure 3b), a remarkable illustration of the transformation of craft to science referred to in the editorial of this issue.

As another example, nuclear power, although still controversial from a policy perspective, is attractive as an efficient and low-emission source of power, given that energy generation accounts for $66 \%$ of all greenhouse-gas emissions, and nuclear energy provides $13 \%$ of the world's electricity supply. ${ }^{9}$ The modern nuclear power plant represents a highly complex, materials-enabled technology. The durability of modern nuclear reactors provides a notable example of teamwork among mechanical designers, neutronics experts, and materials specialists. An impressive range of material types and property requirements is necessary to build an economical and safe nuclear reactor for power generation (Figure 4). 

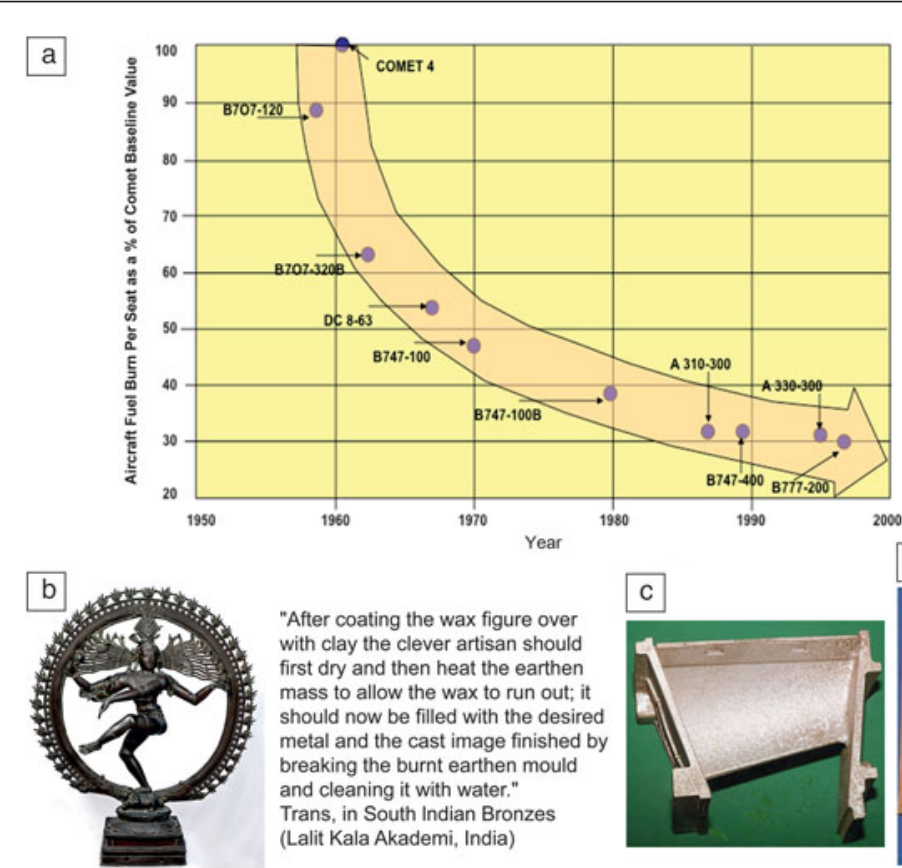

"After coating the wax figure over with clay the clever artisan should first dry and then heat the earthen mass to allow the wax to run out; it should now be filled with the desired metal and the cast image finished by breaking the burnt earthen mould and cleaning it with water." Trans, in South Indian Bronzes (Lalit Kala Akademi, India)
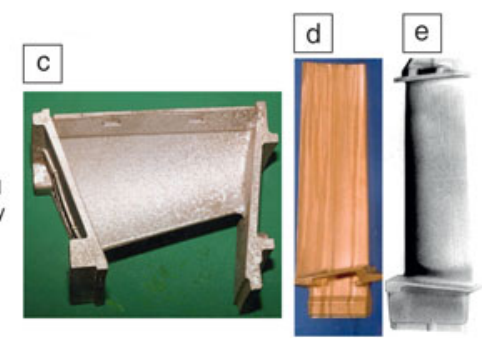

Figure 3. (a) Improvements in aircraft efficiency as illustrated by the decrease in aircraft fuel burned per passenger seat. ${ }^{6}$ Note: A, Airbus; B, Boeing; DC, Douglas. (b) Bronze casting made by the beeswax process in the 12 th century. ${ }^{7}$ (c) Equiaxed, (d) directionally solidified, and (e) single-crystal castings made by the investment casting process. (a) Reproduced with permission from Reference 6. () 1999 Intergovernmental Panel on Climate Change. (c-e) Courtesy of the Defence Metallurgical Research Laboratory, Hyderabad, India.

Apart from more conventional damage mechanisms that arise from high temperature, stress, and a chemically corrosive environment, radiation fluxes affect material properties in nuclear reactors in unusual ways. ${ }^{9}$ For example, radioactive bombardment can make a material stronger but less fracture resistant. Various radiation-induced phases of materials can be formed, each of which affects the mechanical behavior and microstructural stability of the reactor. Spatial variations in neutron flux can cause uneven swelling of the fuel-rod cladding as a result of void formation along the length of the fuel rod, resulting in bowing of the fuel rod. This can cause blockage of the cooling channel that contains the fuel rod, and in the extreme case, reactor shut down would ensue. Swelling in the current generation of light-water reactors, which operate at temperatures of about $300^{\circ} \mathrm{C}$, is minimal, but it could pose serious challenges in the next generation of reactors, which will operate at $400-500^{\circ} \mathrm{C}$.

These examples of changes to the properties of reactorcore materials occur over the lifetime of the component, which typically exceeds 25 years. A major challenge for nuclear materials experts is to develop predictive capabilities that provide the designer with information regarding the extent and consequences of these and many other changes during service. This is particularly so because the small number of reactors being designed and built, coupled with long service lifetimes and limited access to core components, creates a design environment in which there is much less feedback from current products in the field to guide product improvement.

The previous two examples of materials applied to aircraft and nuclear reactors illustrate the engineering impacts of "bulk" materials. The articles in this issue by Taub and Luo and by Kurtis address others, focusing on automobile engineering and the use of cement for infrastructure applications, respectively.

Our third example, semiconductors, moves us toward the nanodomain. Two notable books describe the players and events that led to the birth of the information age: The Coming of Materials Science by Robert Cahn ${ }^{10}$ provides the materials perspective, whereas Crystal Fire: The Birth of the Information Age ${ }^{11}$ by Riordan and Hoddeson describes the events that led to the discovery of the transistor. The emergence of a reliable transistor was driven by a partnership among physicists, chemists, and metallurgists: the invention of the transistor in the 1940s by Bardeen, Shockley, and Brattain; the isolation and chemical identification of the $p$ and $n$ regions by Scaff and Theurer; the growth of dislocation-free crystals by Dash; and the purification of the crystals by Pfann. ${ }^{10}$

It is quite intriguing that the prelude to great discoveries is typically enormous initial skepticism. For example, Frank Whittle's concept of the jet engine was rejected by the UK air ministry, ${ }^{12}$ and Wolfgang Pauli wrote in a 1931 letter to his student, Rudolf Peierls: "One shouldn't work with semiconductors, that is just a mess (eine Schweinerei); who knows whether semiconductors exist at all."10 Indeed, Robert Mehl, one of the fathers of modern metallurgy, dismissed the move to materials science "as a hollow gimmick to obtain funds." 10

Choosing a material composition for an application is only part of the story, however. We have to process the material to shape, join, finish, and repair it at scales varying from a few atomic dimensions to the width of a human hair, a few tens of microns, to the most extraordinarily sizes. The performance of a material in an engineering application is the sum of the processes of synthesis, shaping, and joining. Certainly our progressive ability to manipulate, characterize, and design at the nanoscale or even with single atoms has transformed the landscape of materials choice in virtually every engineering discipline (see Figure 5). The articles in this issue by Mahajan (microelectronics), Dionne et al. (plasmonics), Awschalom and co-authors (quantum computing and spintronics), Gogotsi (carbon), Stupp and co-authors (polymeric biomaterials), and Crabtree et al. (energy storage) address many of these engineering disciplines. Figure 6 provides examples of the significant increases in characterization capabilities at the nanoscale: In their article in this issue, Kaufmann and co-authors describe 


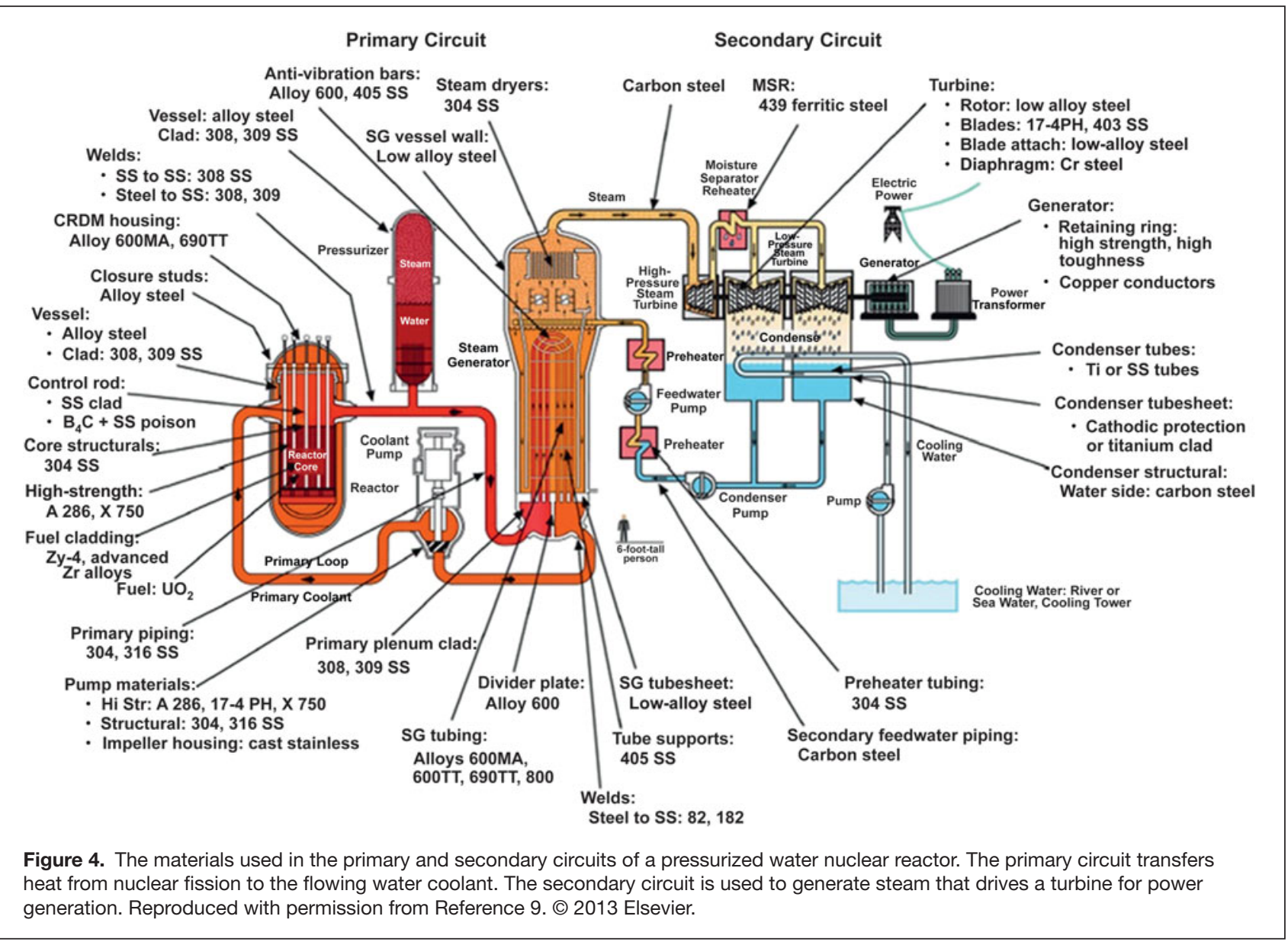

the progress in characterization capability and how this has played into advances in engineering applications.

We have also learned that the architecture of material artifacts can be manipulated to enable hitherto unexplored multidimensional property spaces (Figure 1c). These aspects are explored in this issue in the articles by Greer and co-authors (architected materials), Babu et al. (additive manufacturing), Bose and co-authors (three-dimensional [3D] printing of soft materials), and Someya et al. (large-area, ultraflexible 3D electronics).

\section{Design of materials and products}

Interpretation of the relationships among materials discovery, the underlying science, and the design of a product is not straightforward. Our favorite example is the early application of aluminum alloys in aeronautics and the serendipitous discovery of precipitation-hardened aluminum by Alfred Wilm in Germany in 1909. ${ }^{16}$ Predating this discovery by almost six years, the Wright Brothers used aluminum-copper alloys with $8 \mathrm{wt} \%$ copper in the engine that powered their first historic flight in $1903 .{ }^{17}$ Based on Wilm's discovery, Zeppelins employed in World War I used duralumin, an alloy of aluminum and copper, and the first metal biplane design by Junkers, made of duralumin, flew in 1917. It was only in 1919 that Merica discovered the basis for precipitation hardening. The mechanical basis for hardening emerged in 1922 with concepts proposed by Jeffries and Archer of slip interaction with precipitates. The idea of dislocations followed in 1934 from the work of Orowan, Polanyi, and Taylor, and the first observation of dislocations in $1956 .{ }^{10}$ Aluminium alloys grew steadily in use in airframe structures as the understanding of their strength, fatigue, and stress corrosion improved (see Figure 4 in the article in this issue by Boyer et al.).

In conventional product development, the design process typically stops at component design, with the material being selected from a range of choices. This selection process is followed because the materials development cycle has traditionally used an empirical trial-and-error approach based on the composition-structure-processing-performance paradigm (Figure 7a). This process increasingly takes into account statistical methods such as the Taguchi design of experiments or a process window approach to account for uncertainties in materials behavior in structure, properties, and performance as manufacturing processes are scaled from laboratory concepts to application. Nonetheless, the trial-and-error approach leads to enormous disparities in time scales between the design of a system and its parts and materials development.

Schafrik and Walston ${ }^{18}$ point out, as an example, that the new composite fan blade shape for the General Electric GE90115B engine, which powers the Boeing 777 extended-range 


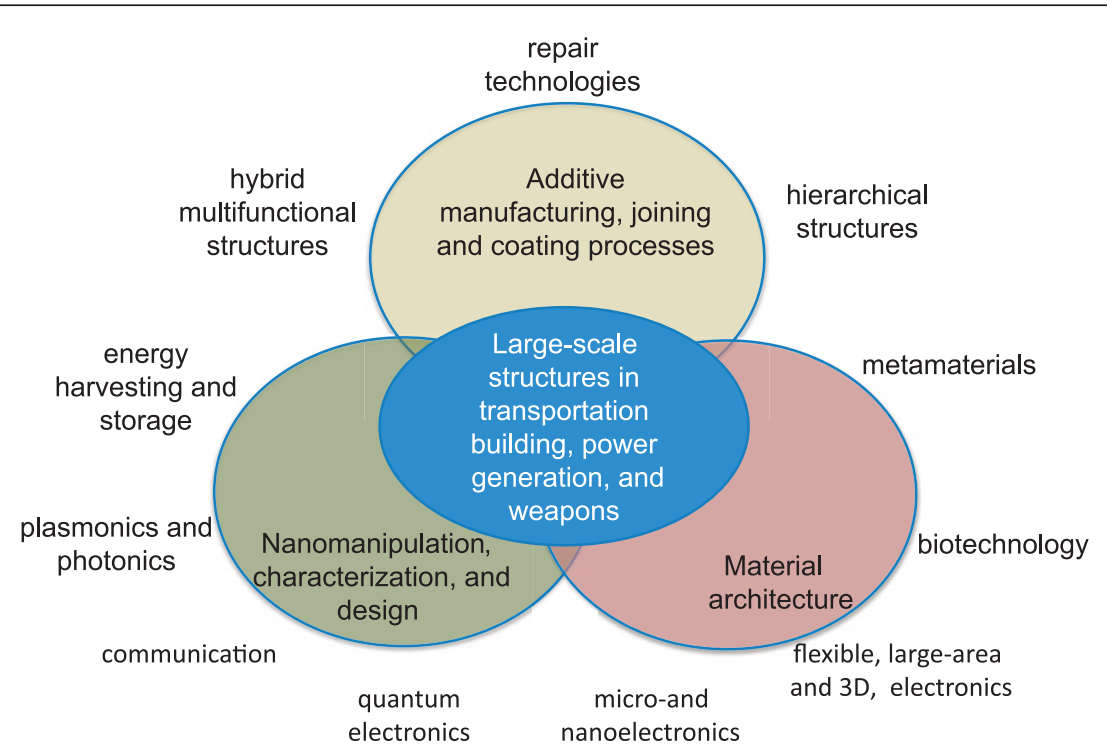

Figure 5. Evolution of materials science and engineering: The advent of the metal age allowed dramatic improvements in transportation, building, power generation, and weaponry. Increasing capabilities in nanomanipulation and characterization, threedimensional (3D) printing, and manufacturing techniques have dramatically expanded the horizons of multiple engineering disciplines.

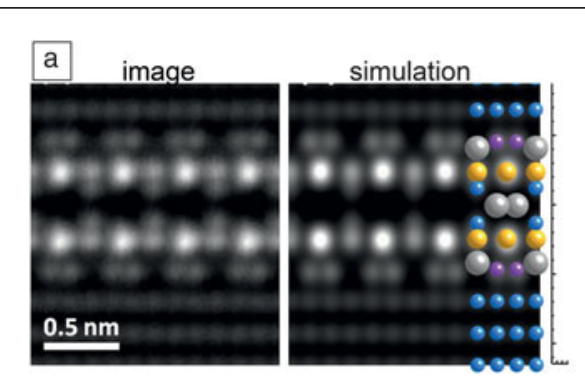

b

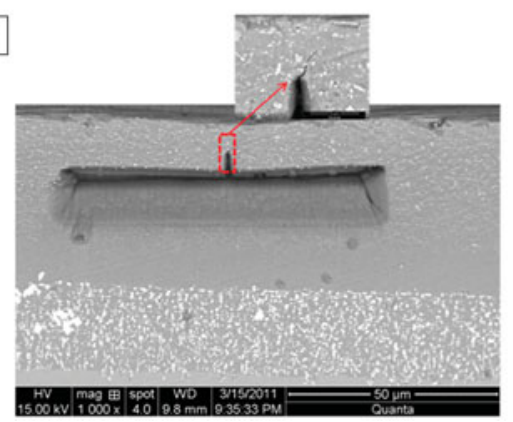

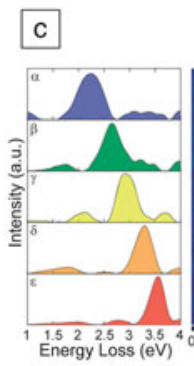

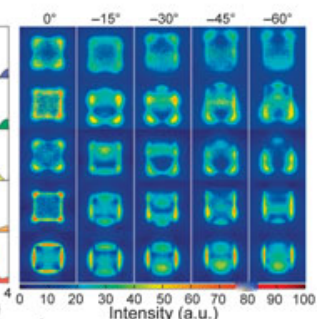

\section{d}

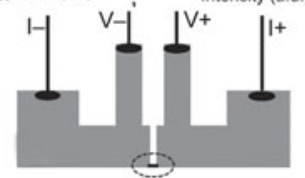

I

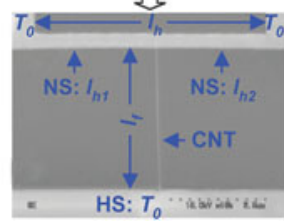

Figure 6. Examples of characterization at the microscale and nanoscale: (a) Atomic structure of precipitates in aluminum alloys imaged by high-angle annular dark-field transmission electron microscopy in aerospace aluminum alloys; (b) microfabrication and testing of fracture samples enables the assessment of the mechanical behavior of coatings on the nickel-based superalloy used in gas turbines; (c) electron energyloss spectrum imaging of plasmon surface resonances of metal nanoparticles; and (d) measuring the thermal conductivity of a single nanotube. (a) Reproduced with permission from Reference 13. () 2011 American Institute of Physics. (b) Courtesy of Vikram Jayaram and Jaya Nagamani, Indian Institute of Science, Bangalore, India.

(c) Reproduced with permission from Reference 14. (c) 2013 Nature Publishing Group. (d) Reproduced with permission from Reference 15. () 1975 Springer. family of aircraft, was designed using a 3D aerodynamic code in 72 iterations within a few weeks in the late 1990s. This component marked the first successful use of a composite fan blade in an aeroengine that is currently the world's largest turbofan engine. Contrast this to the time scales for the development of intermetallic $\gamma$-TiAl, an intermetallic compound in the titanium-aluminum system, one of the few new materials to be introduced into jet engines in recent years (along with polymer-matrix and ceramic-matrix composites). In principle, intermetallic compounds have the capability of being used at higher temperatures than conventional nickel or titanium alloys. Unfortunately, the rate of maturation of any individual intermetallic compound has been exceedingly slow. Kessler and McAndrew first recognized and studied $\gamma$-TiAl in the 1950s. However, it was not until the late 1990s that $\gamma$-TiAl was actually introduced into production in low-pressure turbine airfoils in jet engines. Gilchrist and Pollock have summarized the intervening history of development. ${ }^{19}$

At low temperatures, TiAl fails by cleavage, which is a stress-controlled fracture mode. This fracture mode and the attendant low ductility have been responsible for the extended time period between the inception and first commercial application of $\gamma$-TiAl. It was not until the mid-1990s that the promise of this material became sufficiently clear, prompting renewed interest in the material and warranting serious considerations of ways to design with lowductility materials in critical applications. Designers and materials engineers had long been familiar with the use of ductile materials in critical load-bearing applications in which damage occurs by accumulation of strains, and therefore, control of strain distribution in parts was an intrinsic part of the design exercise.

The promise of $\gamma$-TiAl led to new thinking about the design of the attachment between a relatively ductile nickel-based alloy turbine disk and low-ductility turbine airfoils made of $\gamma$-TiAl. Recognition that $\gamma$-TiAl fails by stresscontrolled fracture stimulated thinking about the distribution of stresses as opposed to strains in the attachment region. When completed, the new attachments had a different geometric shape to spread the reaction forces (stresses) between the disk and airfoil. The new shape reduced the maximum stress by redistributing the contact stresses over a wider area of the disk slots into which the airfoils are attached in the rotating turbine. 


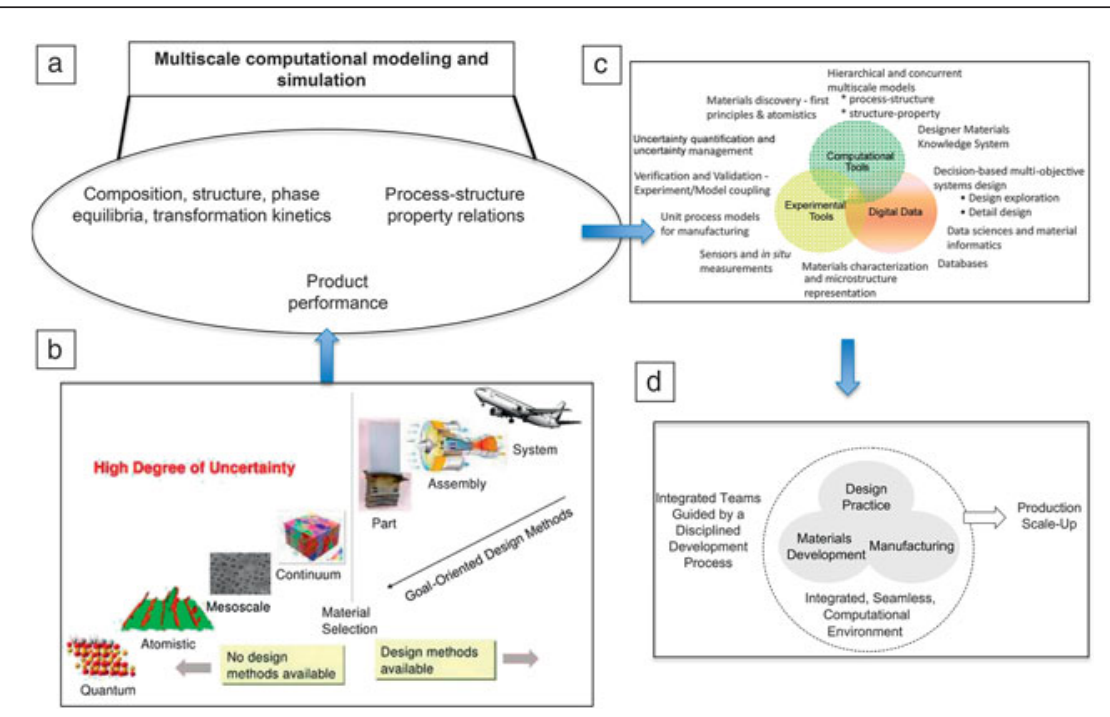

Figure 7. Evolving materials and product design ecosystem: (a) Multiscale modeling and simulation will accelerate product and process optimization and innovation. (b) Trial-anderror methods have dominated materials design from the quantum to the continuum. ${ }^{21}$ (c) Illustration of the multiple aspects of an integrated design methodology. ${ }^{22}$ (d) Accelerated materials insertion demands the integration of disparate teams. (d) Reproduced with permission from Reference 24. () 2004 National Academies Press.

the problem. Therefore, the design process in its entirety must involve reliability, probability, multi-objective optimization, and uncertainty quantification and management at every step with a systems perspective, including design for repairability (as outlined in Figure 7c). ${ }^{21,22}$

As the example of TiAl indicates, a stateof-the-art development practice must integrate the design of materials together with systems engineering and design and the supply chain to achieve accelerated materials insertion, ${ }^{18}$ as shown in Figure $7 \mathrm{~d}$, such that the constraints imposed by external factors not intrinsic to the material capability are understood fairly early in the process. Xiong and Olson explore an example of ICME in their article in this issue. ICME is a powerful concept but not a panacea. Materials researchers and applications developers will need to maintain a realistic and honest dialogue about the evolution of ICME into materials design practices. The process of selection and application of materials into an engineering product involves both an assessment of acceptable risks and learning from past

This new design was first tested in a successful full-scale factory engine test in the mid-1990s, leading to a decision to introduce two stages of $\gamma$-TiAl airfoils into the last two stages of the low-pressure turbine (LPT) in the new GEnx turbofan engine that is used to power the Boeing 787 aircraft and into the last LPT stage of the GEnx model used on the newly modified Boeing 747-8. The result of this decision was a weight reduction in each low-pressure turbine stage of about $200 \mathrm{lb}(90 \mathrm{~kg})$. Cooperation between design engineers and materials technologists enabled this application, including new integrated design and development.

The goal of integrated computational materials engineering ${ }^{20}$ (ICME) is to enable a faster materials development cycle to accelerate materials discovery, development, and application by increasing modeling and simulation-based decisions in each of these steps, as indicated in Figure 7b. The multiscale modeling approach enables a path toward the accurate prediction of properties starting with composition through processing and structure. The materials selection process then maps properties and performance, for example, through Ashby maps. ${ }^{1,2}$ The idea behind these maps is to create material and process selection charts that incorporate design criteria that can simplify the initial survey for potential candidate materials and subsequently examine tradeoffs involving conflicting design objectives in as much detail as necessary. The interaction between material and shape and many other aspects such as cost and sustainability can be built into the method.

However, the path-dependent behavior of materials leading to the final product, the role of extreme value distributions in influencing properties such as fatigue, and the requirement of multiproperty optimization substantially increase the complexity of failures. "For a successful technology," Feynman concluded on the Challenger disaster, "reality must take precedence-for nature cannot be fooled." ${ }^{23}$

\section{Materials, products, and society}

The "valley of death" that lies between the proof of concept of a technology and its transition to a product is applicable to the synthesis and processing of a material, as well as its transformation into engineering artifacts. Making correct choices from myriad possibilities and transforming the choice into a successful engineered application are business decisions that involve the assessment of acceptable risks in a complex and dynamic environment. This is an environment of risks that derive from uncertainties in performance in scaling from the laboratory to the product or system environment; risks that derive from a combination of uncertainties in design, operational, and environmental envelopes; risks that derive from economic, legal, intellectual property, scarcity, regulatory, and health and safety issues, as well as supplier bases and raw material and human resources (see Figure 8).

The myth of Daedalus and Icarus captures wonderfully the uncertain relationship between operational envelopes, design intent, and materials capability. To escape imprisonment on an island, Daedalus built wings for himself and his son Icarus, fashioned from feathers held together with wax. Daedalus warned his son not to fly too close to the sun, as it would melt his wings, and not too close to the sea, as it would dampen them and make it hard to fly. Icarus in his youthful enthusiasm flew too high and too close to the sun.

The cost to produce the material is a fundamental parameter in the value analysis that most potential users perform 


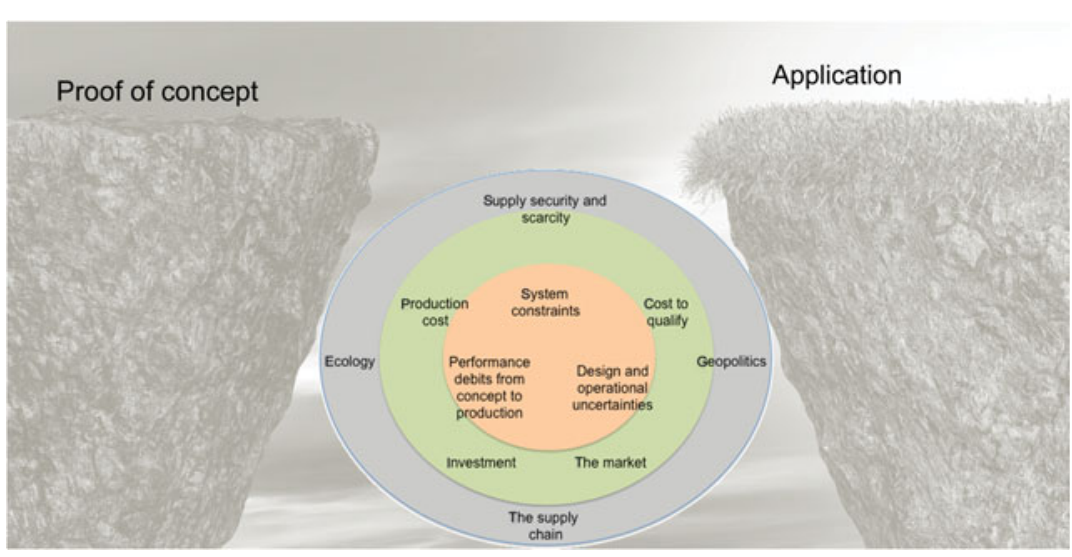

Figure 8. The risk environment in transitioning technology from concept to product included technical, economic, and sociopolitical factors.

one key feature in common, which is to discard the technology-transfer process as a one-way process and to consider it instead as a dynamic of multiply directed interchanges among entrepreneurs, manufacturers, financiers, and researchers, and to provide an appropriate environment where this back-and-forth communication can prosper creatively. ${ }^{24}$ In their articles in this issue, Ball and Galvin et al. explore some of these aspects of transitions to applications and business creation using materials developments.

Food, energy, and materials are the three major categories of commodities in the economy that support societal demands and needs. The role that materials play in the economy must consider increased use of materials with increasing population to sustain growth bal-

before doing any exploratory evaluation of a new material that appears to be attractive but is completely unproven in the market place. Often, the more innovative the new material, the less data are available to support a cost analysis.

An important issue is an accurate estimate of the market size for the new material as a function of time. This is an essential piece of information that allows the seller of the material to determine the time required to realize a positive return on investment for all of the upfront costs. These costs comprise production costs, including capital costs for newer manufacturing facilities if a new material demands it, costs to qualify a new material with representative and design data generation, marketing costs, and so on. It is these costs that often lead to the entrenchment of an older material within a system. Most manufacturing companies are extremely reluctant to obtain material from a sole-source supplier. There are a number of reasons for this, including the disruption that would be caused by a work stoppage at the material supplier, an event such as a fire that damages the production facility, an unexpected shift in quality of the product, or an attempt by the supplier to obtain a price increase.

The "valley of death" is also as much a cultural divide: Researchers in a university see their task as complete with a proof of concept, whereas industry expectations are of a mature prototype with a detailed manufacturing document. A significant issue for materials-related technology transfer is that materials in themselves lie at the back end of various manufacturing steps that go into realizing the final product or system that can be directly linked to societal needs.

The variety of government-originated and business models ${ }^{24}$ that have been directed toward bridging this valley of death all have anced against scarcity of resources and environmental effects. . $^{25,26}$ A typical materials flow cycle is shown in Figure 9. A total life-cycle analysis of material use evaluates the flow of a material from extraction to manufacturing and product utilization to recycling, analyzing discards and environmental and other societal effects at every step along the way. Clearly also, materials are nonrenewable resources at least in time scales involving human endeavor. Mineral resources could approach exhaustion, lie undiscovered, or remain inaccessible because of geopolitical factors. An aspect of life-cycle analysis is the scarcity and security of the materials supply balanced against its projected demand. These are not easily defined terms, and no standard methodologies to assess them exist today. However, they must include geological abundance in relation to a defined time horizon, geopolitical factors, and substitutability on the supply side. Assessment of demand must estimate technology

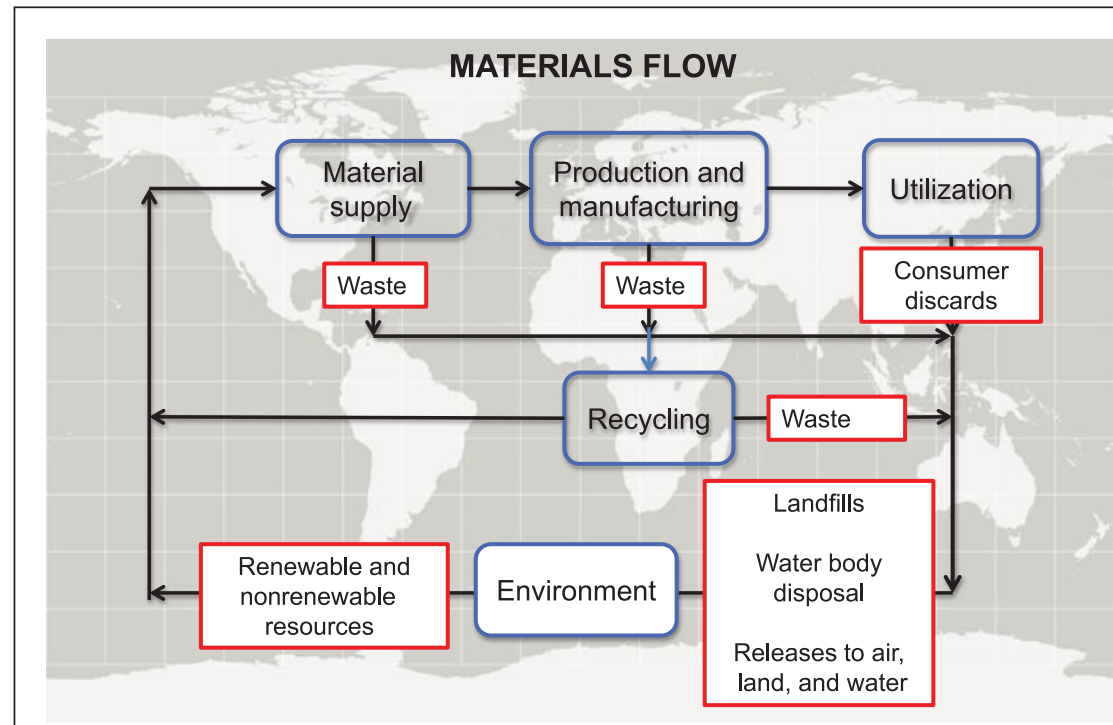

Figure 9. The sustainable application of materials will demand a materials flow analysis of the life cycle associated with product manufacture. Adapted from Reference 25. 


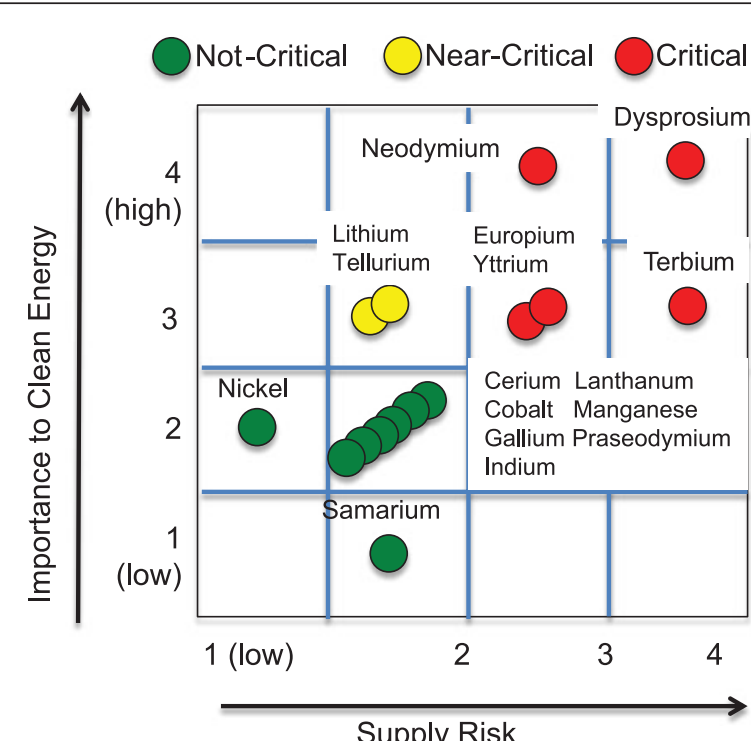

Supply Risk

Figure 10. A life-cycle analysis must include analysis of the security of the materials supply in defined time horizons. An example is shown for materials for clean, renewable energy. Reproduced with permission from Reference 26. (c) 2013 European Union.

penetration of the market among other factors. A typical analysis for supply risk of materials for clean energy is shown in Figure 10. A sustainable materials strategy will need to incorporate an alternative set of design strategies that include design for ecology, substitution, recycling, life extension, and disposability; security of supply; and energy recovery. ${ }^{27}$

In conclusion, we ask how these relationships among materials, processes, and engineering and society will evolve. In his article in this issue, Mark Miodownik peers into the crystal ball 50 years into the future at technological advances and their impact on engineering, society, and culture.

\section{References}

1. M.F. Ashby, Materials Selection in Mechanical Design, 3rd ed. (ButterworthHeinemann, Burlington, MA, 2005).

2. M.F Ashby, H. Shercliff, D. Cebon, Materials Engineering, Science, Processing and Design (Butterworth-Heinemann, Burlington, MA, 2007).

3. N.A. Fleck, V.S. Deshpande, M.F. Ashby, Proc. R. Soc. Lond. A 466, 2495 (2010).

4. M. Miodownik, Stuff Matters: Exploring the Marvelous Materials That Shape Our Man-Made World (Houghton Mifflin Harcourt, Boston, 2014).

5. https://commons.wikimedia.org/wiki/File:\%C3\%84gyptisches_Museum_ Leipzig 254.jpg (accessed October 2015).

6. IPCC Special Report: Aviation and the Global Atmosphere, J.E. Penner, D.H. Lister, D.J. Griggs, D.J. Dokken, M. McFarland, Eds. (Cambridge University Press, Cambridge, UK, 1999).

7. http://www.cse.iitk.ac.in/users/amit/books/img/zimmer-myths_nataraja-cholabronze.jpg (accessed October 2015).

8. R.C. Reed, The Superalloys: Fundamentals and Applications (Cambridge University Press, New York, 2006).

9. S.J. Zinkle, G.S. Was, Acta Mater. 61, 735 (2013).

10. R.W Cahn, The Coming of Materials Science, Pergamon Materials Series (Elsevier Science, Oxford, UK, 2001), vol. 5.

11. M. Riordan, L. Hoddeson, Crystal Fire: The Birth of the Information Age (W.W. Norton, New York, 1997).

12. http://www.bbc.co.uk/history/historic_figures/whittle_frank.shtml (accessed October 2015).
13. C. Dwyer, M. Weyland, L.Y. Chang, B.C. Muddle, Appl. Phys. Lett. 98 201909 (2011).

14. O. Nicoletti, F. de la Peña, R.K. Leary, D.J. Holland, C. Ducati, P.A. Midgley, Nature 502, 80 (2013)

15. M. Fujii, X. Zhang, H. Xie, H. Ago, K. Takahashi, T. Ikuta, H. Abe, T. Shimizu, Phys. Rev. Lett. 95, 065502 (2005)

16. M.E. Fine, Metall. Mater. Trans. A 6, 625 (1975).

17. F.W. Gayle, M. Goodway, Science 266, 1015 (1994).

18. R.E. Schafrik, R. Walston, in Superalloys 2008, R.C. Reed, K.A. Green, P. Caron, T.P. Gabb, M.G. Fahrmann, E.S. Huron, S.A. Woodard, Eds. (TMS, Warrendale, PA, 2008), pp. 3-9.

19. A. Gilchrist, T.M. Pollock, in Structural Intermetallics 2001, K.J. Hemker D.M. Dimiduk, H. Clemens, R. Darolia, H. Inui, J.M. Larsen, V.K. Sikka, M. Thomas, J.D. Whittenberger, Eds. (TMS, Warrendale, PA, 2001), pp. 3-12.

20. Integrated Computational Materials Engineering: A Transformational Discipline for Improved Competitiveness and National Security (National Academies Press, Washington, DC, 2008).

21. D.L. McDowell, J. Panchal, H.-J. Choi, C.C. Seepersad, J.K. Allen, F. Mistree, Integrated Design of Multiscale, Multifunctional Materials and Products (Butterworth-Heinemann, Burlington, MA, 2009).

22. D.L. McDowell, "Materials Genome Initiative for Global Competitiveness 2011" (OSTP-MGI White Paper, Office of Science and Technology Policy, Washington, DC, 2011).

23. R.P. Feynman, What Do You Care What Other People Think? (Norton, New York, 1988)

24. Accelerating Technology Transition: Bridging the Valley of Death for Materials and Processes in Defense Systems (National Academies Press, Washington, DC, 2004).

25. L.A. Wagner, "Materials in the Economy-Material Flows, Scarcity, and the Environment" (US Geological Survey Circular 1221, US Geological Survey, Denver, C0, 2002), http://geology.cr.usgs.gov/pub/circulars/c1221 (accessed October 2015)

26. L. Mancini, C. De Camillis, D. Pennington, Eds., Security of Supply and Scarcity of Raw Materials: Towards a Methodological Framework for Sustainability Assessment (European Union, Luxembourg, 2013).

27. L.Y. Ljungberg, Mater. Des. 28, 466 (2007).

\section{$\mathrm{JAN}$ I S}

\section{Cryogenic Wafer} Probe Stations

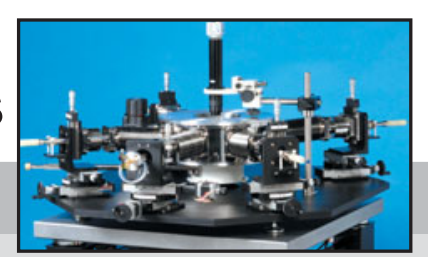

Applications include nano science, materials and spintronics

- $3.2 \mathrm{~K}$ - $675 \mathrm{~K}$; high vacuum or UHV

Up to 8 probes, DC to $67 \mathrm{GHz}$, plus fiber optics

Zoom optics with camera and monitor

- Cooling options: liquid helium, liquid nitrogen or cryogen free

- Horizontal, vertical or vector magnetic field options are available

Contact us today:

sales@janis.com

www.janis.com/Probestations.aspx www.facebook.com/JanisResearch 


\section{Surrounding You with Expertise \& Support}

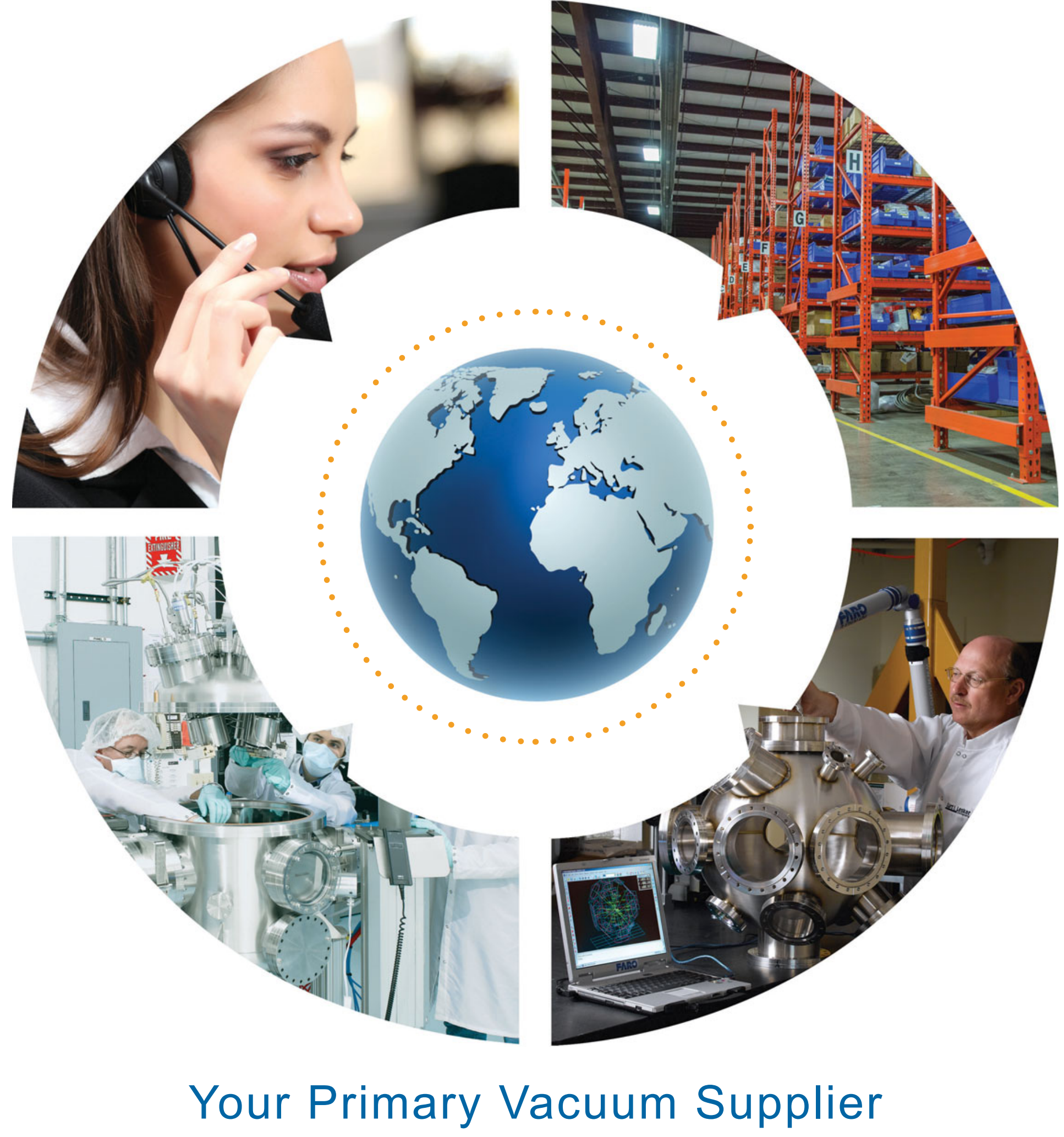

- Highly Professional

Customer Service
- Largest Inventory of Vacuum Components
Renowned Technical

Expertise
Highest Quality

Products Available 